OPEN ACCESS

Edited by:

Anjali Mishra,

Sidney Kimmel Cancer Center,

United States

Reviewed by:

Takayuki Murata,

Fujita Health University, Japan

Kwai Fung Hui,

The University of Hong Kong,

Hong Kong

${ }^{*}$ Correspondence:

Weiguo Xie

wgxie@hotmail.com

Ling Li

Icl115@163.com

Paul Yao

vasilis112@yahoo.com

tThese authors have contributed equally to this work

Specialty section: This article was submitted to

Hematologic Malignancies, a section of the journal

Frontiers in Oncology

Received: 08 November 2018 Accepted: 24 December 2018

Published: 14 January 2019

Citation:

Zhang H, Lu J, Jiao Y, Chen Q, Li M, Wang Z, Yu Z, Huang $X$, Yao A, Gao Q, Xie W, Li L and Yao P (2019) Aspirin Inhibits Natural Killer/T-Cell Lymphoma by Modulation of VEGF

Expression and Mitochondrial Function. Front. Oncol. 8:679. doi: 10.3389/fonc.2018.00679

\section{Aspirin Inhibits Natural Killer/T-Cell Lymphoma by Modulation of VEGF Expression and Mitochondrial Function}

\author{
Hongyu Zhang ${ }^{1 \dagger}$, Jianping $\mathrm{Lu}^{2 \dagger}$, Yun Jiao ${ }^{3 \dagger}$, Qi Chen ${ }^{1}$, Min $\mathrm{Li}^{4}$, Zichen Wang ${ }^{2}$, \\ Zhendong $\mathrm{Yu}^{1}$, Xiaodong Huang ${ }^{4}$, Athena $\mathrm{Yao}^{4}$, Qiong Gao ${ }^{5}$, Weiguo Xie ${ }^{4 *}$, Ling $\mathrm{Li}^{3 *}$ and \\ Paul Yao ${ }^{1,2,3,4 *}$
}

${ }^{1}$ Department of Hematology, Peking University Shenzhen Hospital, Shenzhen, China, ${ }^{2}$ Department of Child Psychiatry, Kangning Hospital of Shenzhen, Shenzhen, China, ${ }^{3}$ Department of Pediatrics, Hainan Maternal and Child Health Hospital, Haikou, China, ${ }^{4}$ Institute of Rehabilitation Center, Tongren Hospital of Wuhan University, Wuhan, China, ${ }^{5}$ Department of Gynecology, The Eighth Affiliated Hospital, Sun Yat-sen University, Shenzhen, China

Extranodal nasal-type natural killer/T-cell lymphoma (NKTCL) is an Epstein-Barr virus (EBV)-associated lymphoma with a strong tendency relapse or be refractory in response to chemotherapy. Development of a new strategy for NKTCL treatment is still quite necessary. In this study, we found that aspirin treatment suppresses VEGF expression in NKTCL SNK-6 cells. Further investigation showed that aspirin treatment increases histone methylation in the range of $-100 \sim 0$ that is proximal to the transcription start site on the VEGF promoter, subsequently decreasing the binding ability of Sp1 to the VEGF promoter with VEGF suppression. Furthermore, aspirin treatment modulates mitochondrial function with increased ROS formation and apoptosis in NKTCL cells. Aspirin treatment alone slightly inhibits NKTCL SNK-6 tumor growth and EBV replication; while in the presence of histone deacetylase inhibitor (HDACi) chidamide (CDM), aspirin significantly suppresses the VEGF signaling pathway with increased ROS overgeneration and EBV inhibition. We also showed that with the addition of chidamide, aspirin significantly suppresses NKTCL tumor growth in both in vitro cell culture and in vivo mouse model with prolonged mouse survival. This is the first time that the potential mechanism for aspirin-mediated VEGF suppression and anti-tumor effect has been discovered, and this study provides a new strategy for anti-tumor drug development for NKTCL treatment based on aspirin-mediated targeting of the VEGF signaling pathway and ROS formation.

Keywords: aspirin, epstein-barr virus, mitochondria, NKTCL, reactive oxygen species

\section{INTRODUCTION}

Extranodal nasal-type natural killer/T-cell lymphoma (NKTCL) is a rare subtype of lymphoma that develops primarily in the nasal cavity or in extranasal sites. It is characterized as an aggressive disease with frequent deletions on chromosome 6q.3-14 (1). NKTCL is closely associated with Epstein-Barr virus (EBV) infection (2). It has NK/T-cell markers (CD3 and CD56) and cytotoxic 
molecules and is characterized by angiocentric and invasive lymphoma cell infiltration and aggressive necrotic lesions in the nasal cavity and palate. Epidemiological study shows that NKTCL is dominant in Asia and Latin America but is very rare in Western countries. NKTCL occurs mostly in younger patients and often is characterized by frequent local progression, but also tends to have extranodal dissemination. Radiotherapy is considered to be the main treatment for early-stage NKTCL and has relatively good outcomes, but the frequent relapse/refractory tendencies of NKTCL may result in a poor prognosis. Therefore, development of a new strategy for the treatment of NKTCL is still quite necessary $(1,3,4)$.

Aspirin (acetylsalicylic acid, ASA), a type of widely used non-steroidal anti-inflammatory drug, has been found to be an effective agent against many human cancers, including colorectal cancer (CRC) (5-7), leukemia (8), and breast cancer (9). Regular use of aspirin can result in improved survival of many cancers, although the effect is relatively weak and has significant side effects $(5,7,10)$. Many potential targets and mechanisms of aspirin have been reported, including heparanase (11), epigenetics (12), NFKB (13), CDH1 (14), and the mitochondria (15), although the detailed mechanism is still largely unknown (16).

Chidamide (CDM, CS055) is a novel benzamide-type histone deacetylase inhibitor (HDACi) (17), a synthetic analog of MS-275 (18), and is currently used for treatment of leukemia (19). We have recently found that CDM inhibits EBV replication through overgeneration of ROS (reactive oxygen species) in EBV-associated tumors (20), and that it also increases p300 over-acetylation in acute myeloid leukemia (AML) cells with dissociation of p300 from HIF1 $\alpha$, subsequently suppressing the HIF1a/VEGF pathway (21). We suppose that CDM may suppress EBV-associated NKTCL tumor growth by inhibition of the HIF1 //VEGF pathway and ROS overgeneration.

In an effort to improve the pharmacological properties of aspirin, we investigated the potential effect and mechanism of aspirin in NKTCL cells. We found that aspirin suppresses VEGF expression through histone methylation and the subsequent decreased association of Sp1 on the VEGF promoter. Furthermore, it modulates mitochondrial function and ROS generation, leading to increased apoptosis in SNK-6 cells. Aspirin treatment alone slightly suppressed tumor growth, while with the addition of histone deacetylase inhibitor chidamide, aspirin significantly potentiated the effect on NKTCL tumor suppression by decreasing VEGF expression and EBV replication, prolonging mouse survival. This is the first time a new aspirin-based strategy has been developed for the treatment of NKTCL with the addition of HDACi chidamide.

\footnotetext{
Abbreviations: ASA, acetylsalicylic acid (Aspirin); CDM, chidamide; ChIP, chromatin Immunoprecipitation; EBV, Epstein-Barr virus; HDAC, Histone deacetylase; HDACi, histone deacetylase inhibitors; NKTCL, Extranodal nasaltype natural killer/T-cell lymphoma; O2, superoxide anions; ROS, reactive oxygen species; Sp1, specificity protein 1; VEGF, vascular endothelial growth factor.
}

\section{MATERIALS AND METHODS}

\section{Reagents and Materials}

The NKTCL cell lines, including HANK-1, NK-92, SNT-8, and SNK-6 cells, were purchased from ATCC and cultured in RPMI 1640 medium containing $2 \mathrm{mmol} / \mathrm{l}$ glutamine supplemented with $100 \mathrm{U} / \mathrm{ml}$ penicillin, $100 \mu \mathrm{g} / \mathrm{ml}$ streptomycin, 10\% human serum and $1,000 \mathrm{U} / \mathrm{ml}$ recombinant human IL-2. All cells were maintained in a humidified incubator with $5 \% \mathrm{CO}_{2}$ at $37^{\circ} \mathrm{C}$.

Antibodies for $\beta$-actin (sc-47778), C/EBP $\alpha$ (sc-7962), EBV Ea-D (sc-58121), EBV ZEBRA (BZ1, sc-53904), Sp1 (sc17824) and VEGF (sc-7269) were obtained from Santa Cruz Biotechnology. Antibodies for acetyl-histone H4 K5, K8, K12, and K16 (H4K5,8,12,16ac, \#PA5-40084) were obtained from Invitrogen. Antibodies for anti-histone $\mathrm{H} 3$ acetyl $\mathrm{K} 9$, K14, K18, K23, K27(H3K9,14,18,23,27ac, ab47915), H4K20me1 (ab9051), H4K20me3 (ab9053), H4R3me1 (ab17339), H3K9me2 (ab1220), H3K9me3 (ab8898), and H3K27me3 (ab6002), H2AX (ab20669) and $\gamma$ H2AX (ab2893) were obtained from Abcam, 3nitrotyrosine (3-NT) was measured by 3 -Nitrotyrosine ELISA Kit (ab116691 from Abcam). Nuclear extracts were prepared using the NE-PER Nuclear and Cytoplasmic Extraction Reagents Kit (Pierce Biotechnology). Protein concentration was measured using the Coomassie Protein Assay Kit (Pierce Biotechnology) per manufacturers' instructions. The siRNA for Sp1 (\# 4457308), ENX-1 (\# 4392420) and negative control (\# AM4636) were obtained from Ambion and transfected by Lipofectamine ${ }^{\circledR} 2000$ Reagent (Invitrogen). Luciferase activity assay was carried out using the Dual-Luciferase ${ }^{\mathrm{TM}}$ Assay System (Promega) and the transfection efficiency was normalized using a cotransfected renilla plasmid.

Acetylsalicylic acid (Aspirin, ASA, \#A5376) was obtained from Sigma. PRC2 specific inhibitor EDD266 (\#2083627-02-3) was obtained from ChemScene llc. Chidamide (CDM, CS055) was supplied by Chipscreen Biosciences (Shenzhen, China) and was dissolved in DMF (dimethyl-formamide). For the in vivo experiments, CDM was suspended in $0.1 \%$ sodium carboxyl methylcellulose and stored at $4^{\circ} \mathrm{C}$.

\section{Construction of Plasmids and Vectors}

The human genomic DNA was prepared from the SNK-6 cells. In order to construct the VEGF reporter plasmid, the VEGF gene promoter (Ensembl gene ID: VEGFA-201 ENST00000230480.10) was amplified by PCR and subcloned into the pGL3-basic vector (\# E1751, Promega) using restriction sites of Mlu I and Hind III with the following primers: Forward: $5^{\prime}$-gcgc-acgcgt- ctg tga acc ttg gtg ggg gtc- $3^{\prime}$ (Mlu I) and Reverse: $5^{\prime}$ - gtac- aagctt- ctc gag agg tca $\mathrm{cct}$ tcc $\mathrm{cgc}-3^{\prime}$ (Hind III). To map VEGF promoter activity, the related deletion promoter constructs were generated by PCR methods and subcloned into the pGL3-basic vector. In order to construct the Sp1 expression plasmid, the human Sp1 cDNA (from Open Biosystems) was amplified by PCR and subcloned into pcDNA3.1 using restriction sites of HindIII and XhoI with the following primers: Forward: $5^{\prime}$ - gtac- aagctt- atg agc gac caa gat cac tcc- $3^{\prime}$ (Hind III) and Reverse: $5^{\prime}$-gcgc- ctcgag - tca gaa gcc att gcc act gat-3' (XhoI). All the vectors were verified 
by sequencing, and detailed information on these plasmids is available upon request (21).

\section{RT Reaction and Real-Time Quantitative PCR}

Total RNA from treated cells was extracted using the RNeasy Micro Kit (Qiagen), and the RNA was reverse transcribed using an Omniscript RT kit (Qiagen). All the primers were designed using Primer 3 Plus software with the Tm at $60^{\circ} \mathrm{C}$, primer size of $21 \mathrm{bp}$, and the product length in the range of 140-160 bp (see Table S1). The primers were validated with the amplification efficiency in the range of 1.9-2.1, and the amplified products were confirmed with agarose gel. Real-time quantitative PCR was run on iCycler iQ (Bio-Rad) with the Quantitect SYBR green PCR kit (Qiagen). The PCR was performed by denaturing at $95^{\circ} \mathrm{C}$ for $8 \mathrm{~min}$, followed by 45 cycles of denaturation at $95^{\circ} \mathrm{C}$, annealing at $60^{\circ} \mathrm{C}$, and extension at $72^{\circ} \mathrm{C}$ for $10 \mathrm{~s}$, respectively. 1 $\mu l$ of each cDNA was used to measure target genes. $\beta$-actin was used as the housekeeping gene for transcript normalization, and the mean values were used to calculate relative transcript levels with the ${ }^{\Delta \Delta}$ CT method per instructions from Qiagen. In brief, the amplified transcripts were quantified by the comparative threshold cycle method using $\beta$-actin as a normalizer. Fold changes in gene mRNA expression were calculated as $2^{-\Delta \Delta C T}$ with $\mathrm{CT}=$ threshold cycle, $\Delta \mathrm{CT}=\mathrm{CT}$ (target gene $)-\mathrm{CT}(\beta$-actin $)$, and the $\Delta \Delta \mathrm{CT}=\Delta \mathrm{CT}$ (experimental)- $\Delta \mathrm{CT}$ (reference) $(21,22)$.

\section{Western Blotting}

Cells were lysed in an ice-cold lysis buffer $(0.137 \mathrm{M} \mathrm{NaCl}$, $2 \mathrm{mM}$ EDTA, $10 \%$ glycerol, $1 \%$ NP-40, $20 \mathrm{mM}$ Tris base, $\mathrm{pH}$ 8.0) with protease inhibitor cocktail (Sigma). The proteins were separated in $10 \%$ SDS-PAGE and further transferred to the PVDF membrane. The membrane was incubated with appropriate antibodies, washed and incubated with HRP-labeled secondary antibodies, and then the blots were visualized using the $\mathrm{ECL}+$ plus Western Blotting Detection System (Amersham). The blots were quantitated by IMAGEQUANT, and final results were normalized by $\beta$-actin $(21,22)$.

\section{Luciferase Reporter Assay}

$1.0 \times 10^{5}$ of SNK-6 cells were seeded in a 6 -well plate with complete medium to grow until they reached $80 \%$ confluence. Cells were then cotransfected by $3 \mu \mathrm{g}$ of VEGF full length or deletion reporter constructs, together with $0.2 \mu \mathrm{g}$ of pRLCMV-Luc Renilla plasmid (from Promega). Then, cells were treated by either $5 \mathrm{mM}$ aspirin or empty control (CTL) for $24 \mathrm{~h}$. After treatment, the cells were harvested and the luciferase activity assays were carried out using the Dual-Luciferase $\mathrm{T}^{\mathrm{TM}}$ Assay System (Promega), and the transfection efficiencies were normalized using a cotransfected Renilla plasmid according to manufacturers' instructions. The VEGF reporter activity from either ASA or control (CTL) was calculated (21).

\section{Chromatin Immunoprecipitation (ChIP)}

Cells were washed and crosslinked using $1 \%$ formaldehyde for $20 \mathrm{~min}$ and terminated by $0.1 \mathrm{M}$ glycine. Cell lysates were sonicated and centrifuged. Five Hundred micrograms of protein were pre-cleared by BSA/salmon sperm DNA with preimmune IgG and a slurry of Protein A Agarose beads. Immunoprecipitations were performed with the indicated antibodies, BSA/salmon sperm DNA and a 50\% slurry of Protein A agarose beads. Input and immunoprecipitates were washed and eluted, then incubated with $0.2 \mathrm{mg} / \mathrm{ml}$ Proteinase $\mathrm{K}$ for $2 \mathrm{~h}$ at $42 \circ \mathrm{C}$, followed by $6 \mathrm{~h}$ at $65 \circ \mathrm{C}$ to reverse the formaldehyde crosslinking. DNA fragments were recovered through phenol/chloroform extraction and ethanol precipitation. A $\sim 150$ bp fragment in the range of $-200 \sim 0$ from the transcription start site on the VEGF promoter was amplified by real-time PCR (qPCR) using the primers provided in Table S1 $(21,22)$.

\section{Immunostaining}

The treated SNK-6 cells were transferred to cover slips coated with $0.1 \%$ gelatin, fixed by $3.7 \%$ formaldehyde at $37^{\circ} \mathrm{C}$ for $15 \mathrm{~min}$, permeabilized by $1 \%$ BSA $+0.2 \%$ Triton X-100 in PBS for $1 \mathrm{~h}$, and then blotted with $40 \mu \mathrm{g} / \mathrm{ml}$ (dilute 1:50) of Ki-67 (MIB-1) mouse monoclonal antibody for $2 \mathrm{~h}$. The cells were then washed three times and the FITC labeled anti-mouse secondary antibody (1:100) was added for blotting for another $1 \mathrm{~h}$. After thorough washing, the slides were visualized and photographed, and the nuclei of cells were stained with 4,6-diamidino-2-phenylindole dihydrochloride (DAPI, \#D9542, from Sigma), and the positive Ki-67 cells were quantitated.

\section{Measurement of ROS Generation}

Treated cells were seeded in a 24-well plate and incubated with $10 \mu \mathrm{M}$ CM-H2DCFDA (Invitrogen) for $45 \mathrm{~min}$ at $37^{\circ} \mathrm{C}$, and then the intracellular formation of reactive oxygen species (ROS) was measured at excitation/emission wavelengths of 485/530 nm using a FLx800 microplate fluorescence reader (Bio-Tek). The data was normalized as arbitrary units $(21,23)$.

\section{Measurement of DNA Breaks}

$8-\mathrm{OHdG}$ formation was measured using an OxiSelect $^{\mathrm{TM}}$ Oxidative DNA Damage ELISA Kit (Cat No. STA320, from Cell Biolabs Inc.) per manufacturers' instructions. The formation of $\gamma \mathrm{H} 2 \mathrm{AX}$ was measured from nuclear extracts by western blotting using $\mathrm{H} 2 \mathrm{AX}$ as the input control (21).

\section{Measurement of Apoptosis}

Apoptosis was evaluated by TUNEL assay using the In Situ Cell Death Detection Kit ${ }^{\mathrm{TM}}$ (Roche). Cells were fixed in $4 \%$ paraformaldehyde and labeled with TUNEL reagents. Stained cells were photographed by a fluorescence microscope and further quantified by FACS analysis. Caspase- 3 activity was determined using the ApoAlert caspase assay kit (Clontech). Treated cells were harvested and $50 \mu \mathrm{g}$ of proteins were incubated with the fluorogenic peptide substrate Ac-DEVD-7amino-4-trifluoromethyl coumarin (AFC). The initial rate of free AFC release was measured using a FL $\times 800$ microplate reader (Bio-Tek) at excitation/emission wavelengths of 380/505 nm, and enzyme activity was calculated as $\mathrm{pmol} / \mathrm{min} / \mathrm{mg}(23)$. 


\section{Measurement of Mitochondrial Function}

Intracellular ATP level was determined using the luciferin/luciferase-induced bioluminescence system. An ATP standard curve was generated at concentrations of $10^{-12}-10^{-3} \mathrm{M}$, and intracellular ATP levels were calculated and expressed as $\mathrm{nmol} / \mathrm{mg}$ protein. Mitochondrial membrane potential $(\Delta \psi \mathrm{m})$ was measured using TMRE (from Molecular Probes T-669) staining. A $600 \mu \mathrm{M}$ T-669 stock solution was prepared using DMSO. Cells were grown on coverslips and immersed in $600 \mathrm{nM}$ TMRE for $20 \mathrm{~min}$ at $37^{\circ} \mathrm{C}$ to load them with dye. The labeling medium was then aspirated and the cells were immersed in $150 \mathrm{nM}$ TMRE to maintain an equal distribution of the fluorophore. The coverslips were mounted with live cells onto confocal microscopes to image the cells using $548 \mathrm{~nm}$ excitation $/ 573 \mathrm{~nm}$ emission filters, and the intensity of TMRE fluorescence was measured using Image J software. Data from 10 to 20 cells were collected for each experimental condition and mean values of fluorescence intensity \pm SEM were calculated (24).

\section{Detection of EBV Copy Number}

Genomic DNA was extracted from treated SNK-6 cells or SNK-6 tumor tissue in mice using a QIAamp DNA Mini Kit (Qiagen). The EBV DNA copy number was measured through qPCR using 50 ng of total DNA with EBV BMRF1 primers (see Table S1), and the results were normalized using cellular $\beta$-actin (primers see Table S1) as an internal control $(25,26)$. The Namalwa cell line, which contains $2 \mathrm{EBV}$ viral genome copies, was used as a standard to prepare calibration curves for both EBV BMRF1 and $\beta$-actin genes, and the EBV viral load was presented as the number of viral genomes per cell $(27,28)$.

\section{Cell Viability and MTT Assay}

Cells were pooled in 12-well plates following exposure to different treatments as indicated at $80 \%$ confluence. Cell viability was analyzed using the MTT (3-(4,5-dimethylthianol-2-yl)- 2,5 diphenyltetrazolium bromide) reduction assay (29). In brief, the cells in each well were aspirated and washed with PBS, and then $0.2 \mathrm{ml}$ of $0.3 \mathrm{mg} / \mathrm{ml}$ MTT solution were added at $25^{\circ} \mathrm{C}$ for $3 \mathrm{~h}$. Thereafter, the precipitated blue formazan product was extracted by incubating samples with $0.1 \mathrm{ml} 10 \%$ SDS (dissolved by $0.01 \mathrm{M} \mathrm{HCl}$ ) overnight at $37^{\circ} \mathrm{C}$. The optical density (OD) of formazan concentrations was determined at $560 \mathrm{~nm}$ and the background was subtracted at $670 \mathrm{~nm}$, then normalized by cell numbers, and expressed as $\mathrm{OD} / 10^{6}$ cells $(21,23)$.

\section{DNA Synthesis by $\left[{ }^{3} \mathrm{H}\right]$-Thymidine Incorporation}

Cell proliferation was evaluated as the rate of DNA synthesis by $\left[{ }^{3} \mathrm{H}\right]$-methylthymidine incorporation (30). Cells were pooled in 24 -well plates until they reached $80 \%$ confluence, and then the indicated chemicals were added and incubated for $24 \mathrm{~h}$. At the end of the treatment, cells were incubated with serum-free media containing ${ }^{3} \mathrm{H}$-methylthymidine $(0.5 \mu \mathrm{Ci} /$ well $)$ for $2 \mathrm{~h}$ and then washed twice with PBS. Cellular DNA was precipitated using $10 \%$ trichloroacetic acid and solubilized with $0.4 \mathrm{M} \mathrm{NaOH}(0.5$ $\mathrm{ml} /$ well). Incorporation of ${ }^{3} \mathrm{H}$-methylthymidine into the DNA was measured in a scintillation counter and was determined as counts per minute (CPM) (21).

\section{Colony Formation in Soft Agar}

This assay is a method for evaluating the ability of individual cell lines to grow in an anchorage-independent manner. Cells were resuspended in DMEM containing 5\% FBS with $0.3 \%$ agarose and layered on top of $0.5 \%$ agarose in DMEM on $60-\mathrm{mm}$ plates. One thousands of cells were seeded in $60 \mathrm{~mm}$ soft agar dishes for 30 days. The dishes were examined twice per week, and colonies that grew beyond $50 \mathrm{~mm}$ in diameter were scored as positive. Each experiment was done in quadruplicate (21).

\section{Migration and Invasion Assays}

Cell migration and invasion assays were performed in 24-well chemotaxis plates with an $8 \mu \mathrm{m}$ polycarbonate filter membrane. The plates were coated with $20 \mu \mathrm{g}$ Matrigel for invasion assays and uncoated for migration assays. Invasion and migration were expressed as the number of migrated cells bound per microscopic field and averaged from at least four fields per assay in at least 4 experiments $(31,32)$.

\section{Animals}

$\mathrm{Balb} / \mathrm{c}$ athymic nude male mice (6 weeks old) were obtained from the Guangdong Medical Animal Center. All procedures involving mice were conducted in accordance with $\mathrm{NIH}$ regulations concerning the use and care of experimental animals, and were approved by the Institutional Animal Care and Use Committee (from Peking University Shenzhen Hospital). The $2 \times 10^{6}$ viable treated tumor cells were washed, harvested in PBS, and then injected into the lateral tail vein in a volume of $0.1 \mathrm{ml}$. Two days after the implantation of the primary xenograft, the mice were treated with either aspirin (ASA) or $25 \mathrm{mg} / \mathrm{kg}$ of body mass of CDM ( $0.1 \%$ sodium carboxyl methylcellulose as vehicle), or a combination of ASA/CDM via oral gavage 3 times a week. The experimental mice were separated into 5 groups $(n=9)$ as follows. Group 1 (CTL): Chemical vehicle $(0.1 \%$ sodium carboxyl methylcellulose) as control; Group 2 (ASA-100): Low-dose of aspirin (100 mg/kg); Group 3 (ASA-400): High-dose of aspirin (400 mg/kg); Group 4: (ASA-100/CDM): Low-dose of aspirin $(100 \mathrm{mg} / \mathrm{kg})$ plus CDM $(25 \mathrm{mg} / \mathrm{kg}$ in $0.1 \%$ sodium carboxyl methylcellulose); Group 5 (ASA-400): High-dose of aspirin (400 $\mathrm{mg} / \mathrm{kg}$ ) plus CDM $(25 \mathrm{mg} / \mathrm{kg})$. Mice were monitored for changes in body weight and sacrificed when values fell below $20 \%$ of the initial weight. The lungs of sacrificed mice were isolated and fixed in $10 \%$ formalin. The number of surface metastases per lung was determined under a dissecting microscope. Formalin-fixed, paraffin-embedded tumor tissue from the lungs were sectioned to $4 \mathrm{~mm}$ thickness, and the histopathological analyses were performed with $\mathrm{H} \& \mathrm{E}$ staining. Images were taken using a Carl Zeiss MIRAX MIDI slide scanner, and analyses were performed using a 3DHISTECH Pannoramic Viewer. The tumor tissues were isolated for in vivo monitoring of superoxide anion release and gene expression of tumor tissues were measured through real time PCR for mRNA and Western Blotting for protein levels (21). 


\section{In vivo Superoxide Release}

Superoxide anion $\left(\mathrm{O}_{2}^{-}\right)$release from tumor tissues was determined using a luminol-EDTA-Fe enhanced chemiluminescence (CL) system supplemented with DMSOTBAC (Dimethyl sulfoxide-tetrabutyl-ammonium chloride) solution for extraction of released $\mathrm{O}_{2}^{-}$from tissues, as described previously (23). Superoxide levels were calculated from the standard curve generated by the xanthine/xanthine oxidase reaction (21).

\section{Statistical Analysis}

The data was given as mean \pm SEM; all of the experiments were performed at least in quadruplicate unless otherwise indicated. One-way ANOVA followed by the Bonferroni post hoc test was used to determine statistical significance of different groups. The mouse survival curve was determined through Kaplan-Meier survival analysis using SPSS 22 software, and a $P<0.05$ was considered significant (21).

\section{RESULTS}

\section{Aspirin Treatment Suppresses VEGF Expression in NKTCL Cells}

It has been previously reported that aspirin inhibits VEGF and tumor growth by direct downregulation of $\mathrm{Sp} 1$ in colon cancer cells (33). In this study, we evaluated the effect of aspirin on the gene expression of VEGF and Sp1 in different kinds of NKTCL cells. In Figure 1, the SNK-6 cells were treated with different concentrations of aspirin: $0,1,2,5$, and $10 \mathrm{mM}$. The results showed that 1 and $2 \mathrm{mM}$ of aspirin had no effect, while 5 and $10 \mathrm{mM}$ of aspirin decreased VEGF mRNA by 46 and 58\%, respectively. On the other hand, there was no difference in $\mathrm{Sp} 1$ expression (see Figure 1A). We then measured the effect of aspirin on the protein levels of VEGF and Sp1. The results showed that 1 and $2 \mathrm{mM}$ of aspirin had no effects on protein expression, while 5 and $10 \mathrm{mM}$ of aspirin suppressed VEGF expression by 38 and $53 \%$, respectively, and Sp1 had no effect. Then, we measured the effect of aspirin on HANK-1 (see Figure S1A), NK92 (see Figure S1B) and SNT-8 cells (see Figure S1C), and found that aspirin had no effect on Sp1 expression, while 5 and $10 \mathrm{mM}$ of aspirin treatment significantly suppressed VEGF expression. These results indicate that aspirin treatment suppresses VEGF expression in NKTCL cells, but does not suppress Sp1 expression.

\section{Aspirin Regulates VEGF Expression Through Histone Methylation and Subsequently Decreased Association of Sp1 on the VEGF Promoter}

We investigated the potential molecular mechanism for aspirinmediated VEGF suppression. A series of progressive 5'-promoter deletion constructs for the VEGF promoter were generated, and these constructs were transfected into SNK-6 cells for the analysis of VEGF reporter activity in the presence of $5 \mathrm{mM}$ aspirin (ASA).
We found that VEGF-induced reporter suppression occurred among the $-2000,-1500,-1000,-500,-400,-300,-200$ and -100 deletion constructs (numbered according to Ensembl gene ID: VEGFA-201 ENST00000230480.10, transcription start site was marked as 0 ), while activity did not decrease in the pVEGF0 deletion reporter construct, indicating that aspirin-responsive transcriptional element is located in the range of $-100 \sim 0$ on the VEGF promoter (see Figure 2A). The transcription factor databases TESS revealed many potential binding motifs, including 1 of $\mathrm{C} / \mathrm{EBP} \alpha$ and 6 of Sp1 binding sites (marked in red) located at the range of $-100 \sim 0$ on the VEGF promoter (see Figure 2B). We then mutated these potential binding motifs in the -100 deletion reporter construct (see Figure 2C), and VEGF mutation reporter assay showed that mutation of any Sp1 binding motif at either $-91,-81,-69,-59,-49$, or -44 significantly decreased pVEGF-100 reporter activity compared to the pVEGF100 wild type reporter. This partly mimicked the effect of aspirininduced VEGF suppression, while mutation of $\mathrm{C} / \mathrm{EBP} \alpha$ at -15 did not show any effects (see Figure 2C). We then mutated all of the 6 Sp1 binding sites in one pVEGF-100 construct (pVEGF$100 / \mathrm{M}-\mathrm{Sp} 1$ ), and the cells were transfected with pVEGF-100 wild type (pVEGF-100), pVEGF-100/M-Sp1, pVEGF-100 wild type with siRNA for Sp1(pVEGF-100/siSp1), pVEGF-100 with $5 \mathrm{mM}$ ASA (pVEGF-100/ASA), or pVEGF plus $5 \mathrm{mM}$ ASA together with the Sp1 overexpression plasmid (pVEGF-100/ASA/ $\uparrow \mathrm{Sp} 1$ ) for $24 \mathrm{~h}$. Our results showed that mutation of 6 of the Sp1 binding sites (pVEGF-100/M-Sp1) significantly decreased pVEGF-100 reporter activity and resulted in reporter activity similar to that of the treatment of pVEGF-100/ASA and pVEGF-100/siSp1. In addition, ASA-induced pVEGF-100 reporter suppression (pVEGF-100/ASA) could not be restored by Sp1 overexpression (pVEGF-100/ASA/ $\uparrow \mathrm{Sp} 1$ ), indicating that aspirin-induced VEGF suppression may be due to ASA-induced dissociation of Sp1 in the range of $-100 \sim 0$ on the VEGF promoter (see Figure 2D). We then conducted ChIP analysis using antibodies of Sp1 and $\mathrm{C} / \mathrm{EBP} \alpha$ (see Figure 2E); the results showed that Sp1 binding ability on the VEGF promoter was significantly decreased in the treatments of both the 5 and the $10 \mathrm{mM}$ ASA groups, while $\mathrm{C} / \mathrm{EBP} \alpha$ binding ability did not change (see Figure 2E). Given the fact that $\mathrm{Sp} 1$ protein expression levels did not change during ASA treatment, ASA-induced decreased association of Sp1 on the VEGF promoter may be due to ASA-induced epigenetic changes in the range of $-100 \sim 0$ on the VEGF promoter. We first evaluated histone acetylation on the VEGF promoter using the acetyl-histone $\mathrm{H} 4(\mathrm{~K} 5, \mathrm{~K} 8, \mathrm{~K} 12, \mathrm{~K} 16)$ antibody that recognizes histone $\mathrm{H} 4$ acetylated at lysines 5, 8, 12, or 16 and the acetyl-histone H3 (K9, K14, K18, K23, K27) antibody that recognizes histone $\mathrm{H} 3$ acetylated at lysines 9, 14, 18, 23, or 27 by ChIP analysis (see Figure S2A). The results showed that there was no significant difference in either histone $\mathrm{H} 3$ or $\mathrm{H} 4$ acetylation. We then measured histone methylation on the VEGF promoter. We first evaluated histone $\mathrm{H} 4$ methylation on the VEGF promoter (see Figure S2B) and found that aspirin did not have any effect on histone H4 methylation. We then evaluated the effect of aspirin on histone $\mathrm{H} 3$ methylation (see Figure 2F). The results showed that aspirin treatment had no effect on the methylation of $\mathrm{H} 3 \mathrm{~K} 9 \mathrm{me} 2$ or $\mathrm{H} 3 \mathrm{~K} 9 \mathrm{me} 3$, while 


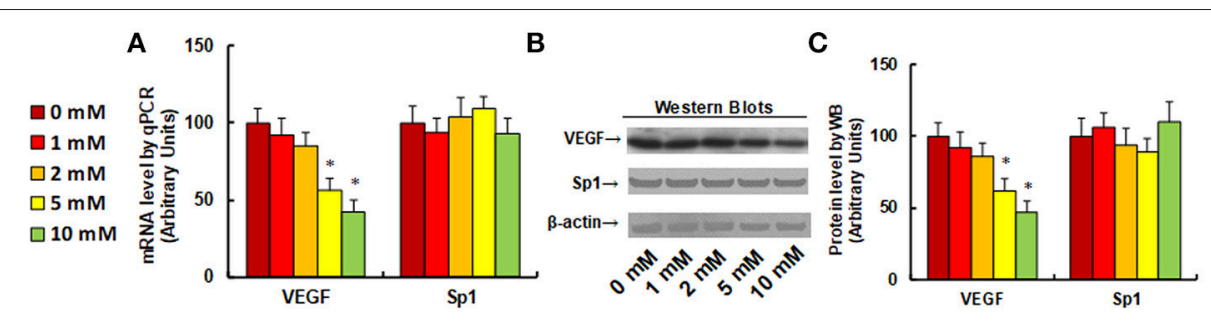

FIGURE 1 | Aspirin treatment suppresses VEGF expression in SNK-6 cells. SNK-6 cells were treated by ASA with different concentrations of $0,1,2,5$, and $10 \mathrm{mM}$ for $24 \mathrm{~h}$, and then the cells were used for the analysis of gene expression. (A) mRNA level by qPCR, $n=4$. (B) Representative pictures for Western Blotting. (C) Quantitation of protein levels for (B), $n=5 .{ }^{*} P<0.05$, vs. CTL group. Data are expressed as mean \pm SEM.

methylation of H3K27me3 increased to 156 and $186 \%$ by 5 and $10 \mathrm{mM}$ aspirin treatment respectively. In order to further confirm that VEGF suppression is due to aspirin-induced H3K27me3 modification on the VEGF promoter, the SNK-6 cells were treated by either siRNA for EZH2, a catalytic subunit of PRC2 that is responsible for H3K27me3 methylation (34), or PRC2 specific inhibitor EED226 (34), and the cells were harvested for further analysis. We first measured mRNA expression. The results showed that EZH2 mRNA expression was decreased to 31 and 26\%, respectively, in EZH2 siRNA cell line A (ASA/siEZH2A) and B (ASA/siEZH2-B) compared to the control (CTL) group, indicating a successful knockdown by EZH2 siRNA for SNK6 cell line A and B. EED mRNA expression did not change in response to the different treatments. Additionally, VEGF mRNA was decreased to $61 \%$ as a result of aspirin (ASA) treatment compared to the CTL group, while both EZH2 siRNA and PRC2 inhibitor EED226 treatment completely restored the effect of aspirin (see Figure 2G). We then measured histone methylation on the VEGF promoter using ChIP analysis (see Figure 2H). The results showed that $\mathrm{H} 3 \mathrm{~K} 9 \mathrm{me} 2$ modification did not change in response to any of the treatments, while H3K27me3 modification increased to $167 \%$ in response to aspirin treatment (ASA) compared to the CTL group, and either the EZH2 siRNA treatments (ASA-siEZH2A or ASAsiEZH2B), or EED226 treatment completely restored this effect. We finally measured VEGF reporter activity (see Figure 2I), and the results showed that treatments of either EZH2 siRNA or EED226 completely restored aspirin-induced decreased VEGF reporter activity. Our results indicate that aspirin-induced VEGF suppression in SNK-6 cells is due to aspirin-mediated H3K27me3 histone methylation and the subsequently dissociation of Sp1 on the VEGF promoter.

\section{Aspirin Treatment Modulates ROS Generation, DNA Damage, Mitochondrial Function and Apoptosis in SNK-6 Cells}

We evaluated the potential effect of aspirin treatment on molecular consequences in SNK-6 cells. We first measured the effect of aspirin treatment on oxidative stress. The results showed that 5 and $10 \mathrm{mM}$ of aspirin increased ROS formation to 168 and 187\%, respectively (see Figure 3A), and increased 3-nitrotyrosine formation to 149 and 167\%, respectively (see Figure 3B), while 1 and $2 \mathrm{mM}$ of aspirin had no significant effects. We also measured the effect of aspirin on DNA damage. The results showed that 5 and $10 \mathrm{mM}$ of aspirin increased 8-OHdG formation to 195 and $219 \%$, respectively, while 1 and $2 \mathrm{mM}$ of aspirin showed no effect (see Figure 3C). On the other hand, 2, 5, and $10 \mathrm{mM}$ of aspirin increased $\gamma \mathrm{H} 2 \mathrm{AX}$ formation to 168,206 , and $253 \%$, respectively (see Figures 3D,E). We then measured the effect of aspirin on mitochondrial function. The results showed that 2, 5 and $10 \mathrm{mM}$ of aspirin decreased ATP intracellular levels by 18,40 , and $57 \%$, respectively (see Figure $3 F$ ), while 5 and $10 \mathrm{mM}$ of aspirin decreased mitochondria membrane potential $(\Delta \Psi \mathrm{m})$ by 35 and $43 \%$, respectively (see Figure $3 \mathrm{G}$ ). We finally measured the effect of aspirin on apoptosis in SNK-6 cells. We found that 5 and $10 \mathrm{mM}$ of aspirin increased caspase- 3 activity to 202 and $253 \%$, respectively (see Figure $3 \mathbf{H}$ ), and increased apoptosis rate to 320 and 390\%, respectively (see Figures 3I,J). Our results indicate that higher doses of aspirin (5 and $10 \mathrm{mM}$ ) could achieve significant molecular consequences in SNK-6 cells, while lower doses ( 1 and $2 \mathrm{mM}$ ) of aspirin have little effect.

\section{Chidamide (CDM) Treatment Alone Slightly Suppresses VEGF Expression, Increases ROS Formation and Apoptosis, and Slightly Increases EBV Replication in SNK-6 Cells}

In this study, we show that aspirin induces VEGF suppression and oxidative stress in NKTCL cells. It has been previously reported that chidamide induces oxidative stress $(18,20,35)$ and VEGF signaling pathway in cancer cells (21). If chidamide could achieve the similar effect in NKTCL cells, this would point to the possibility that a combination of aspirin and chidamide may exert a synergistic effect in inducing VEGF suppression and oxidative stress in NKTCL cells. In Figure S3, we evaluated the potential effect of histone deacetylase inhibitor chidamide on SNK-6 cells. The results showed that 3 and $4 \mu \mathrm{M}$ of chidamide decreased VEGF expression by 29 and 32\%, respectively. In addition, they increased ROS formation to 134 and $147 \%$, respectively (see Figure S3B), and also increased apoptosis rate to 219 and 245\%, respectively (see Figure S3C) compared to the $0 \mu \mathrm{M}$ treatment. On the other hand, 1 and $2 \mu \mathrm{M}$ of chidamide showed no effect on NKTCL cells. We then evaluated the effect of chidamide on EBV virus in SNK-6 cells. The results showed that 3 and $4 \mu \mathrm{M}$ of chidamide increased BZLF1 mRNA 


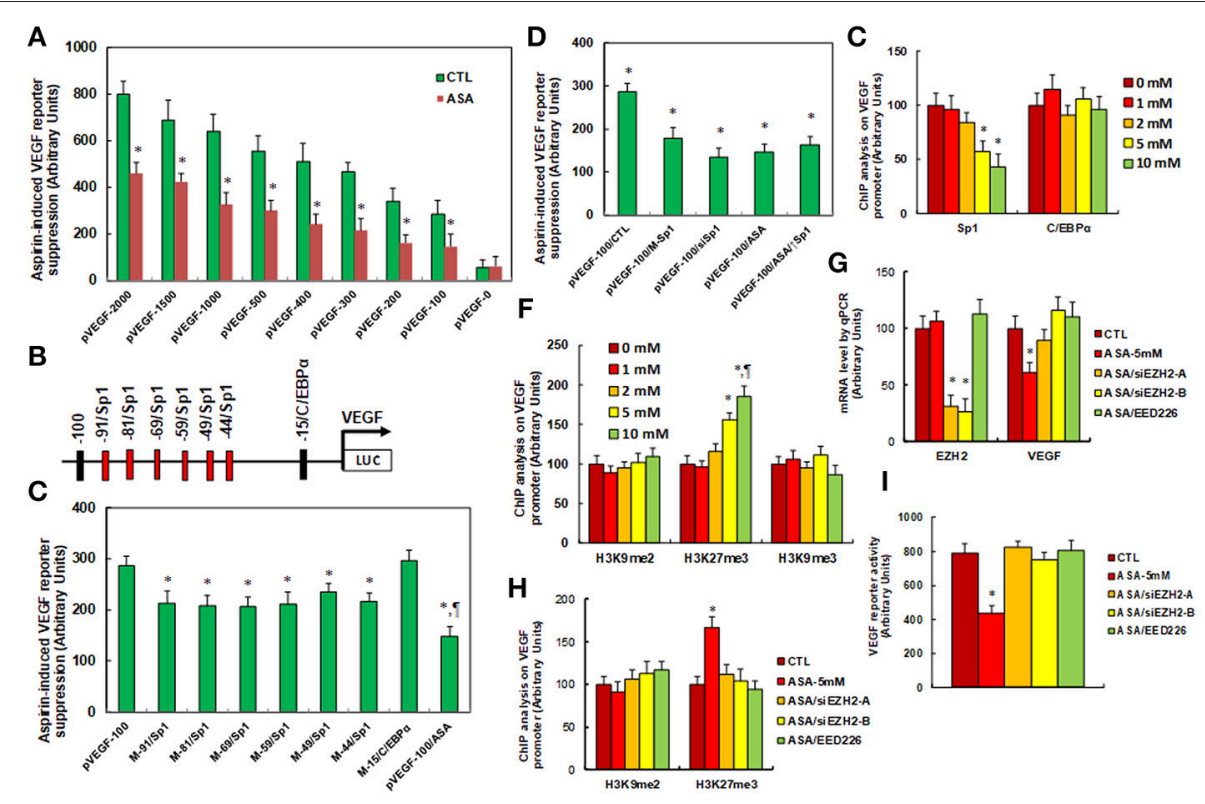

FIGURE 2 | Aspirin regulates VEGF expression through histone methylation and the subsequent decreased association of Sp1 on the VEGF promoter. (A) The SNK-6 cells were transiently transfected by either VEGF full length (pVEGF-2000) or deletion reporter plasmids. After $24 \mathrm{~h}$, the cells were treated by either control (CTL) or $5 \mathrm{mM}$ ASA for $24 \mathrm{~h}$, and the VEGF reporter activities were calculated, $n=4$. ${ }^{*} P<0.05$, vs. pVEGF-2000 group, $n=4$. (B) The schematic picture for the potential transcriptional binding motif in the range of $-100 \sim 0$ (from transcription start site) on the VEGF promoter in addition to the 6 potential Sp1 binding sites are marked in red. (C) The SNK-6 cells were transiently transfected by either wild type VEGF deletion (-100) reporter construct (pVEGF-100), or single point mutation of Sp1 and $\mathrm{C} / \mathrm{EBP} \alpha$ at the site shown in (B), then treated with either control or $5 \mathrm{mM}$ ASA for $24 \mathrm{~h}$, and the VEGF reporter activities were calculated. (D) The SNK-6 cells were transiently transfected by either CTL (transfected with control siRNA plus empty luciferase vector), or wild type VEGF deletion (-100) reporter construct (pVEGF-100), or single point mutation of 6 Sp1 sites in one reporter (pVEGF-100/M-Sp1), and then treated with either siSp1(pVEGF-100/siSp1), or 5 mM ASA (pVEGF-100/ASA) alone, or ASA together Sp1 overexpression plasmid (pVEGF-100/ASA/ $\uparrow S p 1$ ) for $24 \mathrm{~h}$ and the VEGF reporter activities were calculated. (E) SNK-6 cells SNK-6 cells were treated by ASA with different concentrations of $0,1,2,5$, and $10 \mathrm{mM}$ for $24 \mathrm{~h}$, then the cells were used for ChIP analysis by Sp1 and C/EBP $\alpha$ antibodies, and the VEGF promoter in the range of $-200 \sim 0$ was amplified and measured by qPCR, $n=5$. ${ }^{*} P<0.05$, vs. $0 \mathrm{mM}$ group. (F) SNK-6 cells were used for ChIP analysis by H3K9me2, H3K27me3, and H3K9me3 antibody, respectively, and the VEGF promoter in the range of $-200 \sim 0$ was amplified and measured by qPCR, $n=5$. (G-I) The SNK-6 cells were treated by control (CTL), $5 \mathrm{mM}$ aspirin (ASA-5 mM), aspirin with EZH2 siRNA cell line (A,B) (ASA/siEZH2-B), or 2 $\mu \mathrm{M}$ of EED266 for $24 \mathrm{~h}$, and the cells were harvested for further analysis. (G) mRNA levels by qPCR for EZH2, EED, and VEGF, $n=4$. (H) ChIP analysis by H3K9me2 and H3K27me3, respectively on the VEGF promoter, $n=5$. (I) VEGF reporter activity assay, $n=5$. ${ }^{*} P<0.05$, vs. OmM group; $\mathbb{\text { Il }} P<0.05$, vs. $5 \mathrm{mM}$ group. Results are expressed as mean $\pm \mathrm{SEM}$.

expression to 168 and $159 \%$, respectively. It also increased BMRF1 mRNA expression to 156 and 169\%, respectively (see Figure S3D) compared to $0 \mu \mathrm{M}$ chidamide treatment, while 1 and $2 \mu \mathrm{M}$ of chidamide had no effect on NKTCL cells. We also measured the effect of chidamide on EBV replication. The results showed that $2 \mu \mathrm{M}$ of chidamide slightly increased EBV DNA copies to $128 \%$, while other doses showed no effect. The results indicate that chidamide alone has small effects on SNK-6 cells.

\section{Aspirin Treatment Increases ROS Generation While Suppressing VEGF Expression and EBV Replication in SNK-6 Cells. Chidamide Significantly Potentiates This Effect}

We first evaluated the effect of aspirin and chidamide on ROS generation. The results showed that aspirin treatment of $2 \mathrm{mM}$ (ASA-2 mM) or $5 \mathrm{mM}$ (ASA-5 mM) alone increased ROS generation to 137 and 156\%, respectively, compared to the control (CTL) group. In addition, a combination of chidamide (CDM) with either $2 \mathrm{mM}$ (ASA-2 mM/CDM) or $5 \mathrm{mM}$ of aspirin (ASA-5 mM/CDM) further increased ROS generation to 216 and $278 \%$, respectively (see Figure 4A). We then evaluated the effect of aspirin and chidamide on VEGF expression. The results showed that $2 \mathrm{mM}$ of aspirin treatment (ASA-2 mM) alone had no effect, while $5 \mathrm{mM}$ aspirin (ASA$5 \mathrm{~mm}$ ) decreased VEGF mRNA levels by $28 \%$. On the other hand, a combination of chidamide (CDM) with either $2 \mathrm{mM}$ (ASA-2 mM/CDM) or $5 \mathrm{mM}$ of aspirin (ASA-5 mM/CDM) significantly decreased VEGF mRNA levels by 49 and 68\%, respectively, and had no effect on Sp1 expression (see Figure 4B). We also measured protein expression (see Figures 4C,F), and found that treatments of ASA-5 mM, ASA-2 mM/CDM and ASA-5mM/CDM decreased VEGF protein levels by 29, 46, and $69 \%$, respectively, but had no effect on Sp1 expression. We then measured mRNA expression of BZLF1 and BMRF1, which is responsible for EBV activation. The results showed that treatments of ASA-5 mM, ASA-2 mM/CDM and ASA$5 \mathrm{mM} / \mathrm{CDM}$ decreased BDLF1 mRNA levels by 29, 46, and $69 \%$, respectively, and treatments of ASA-2mM/CDM and ASA$5 \mathrm{mM} / \mathrm{CDM}$ decreased BMRF1 mRNA levels by 36 and 43\%, 


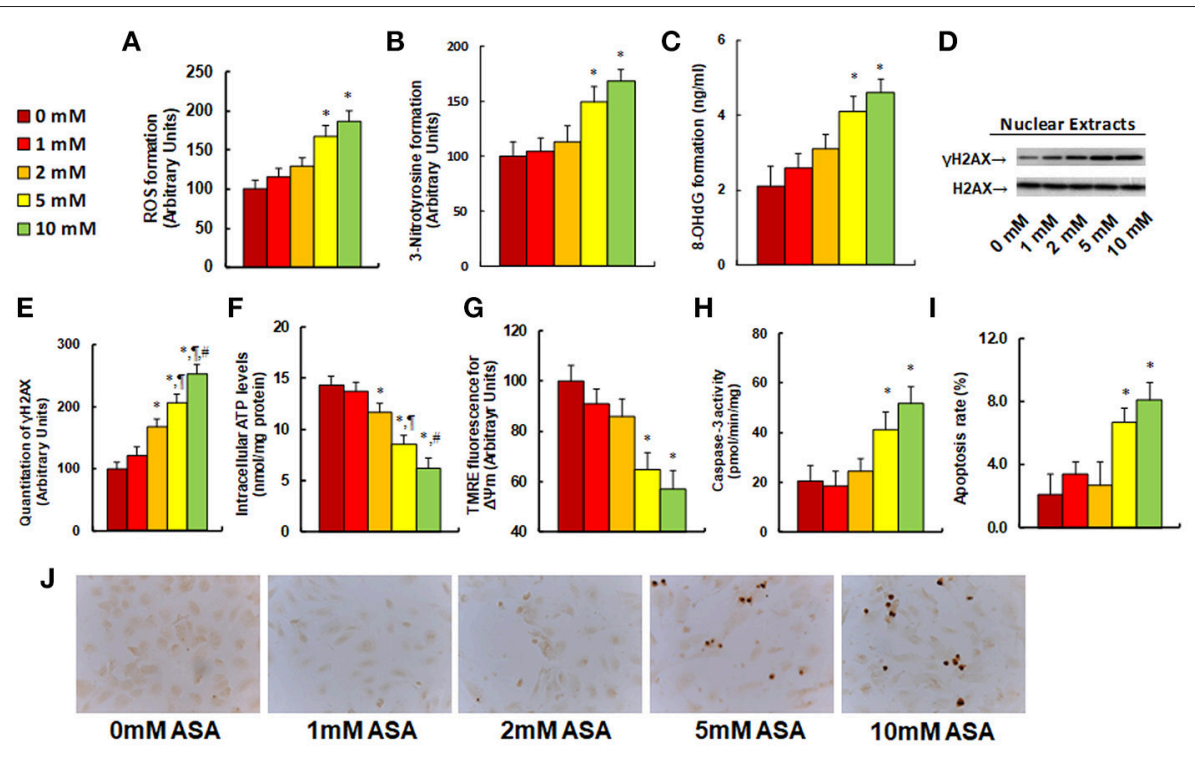

FIGURE 3 | Aspirin treatment modulates ROS generation, DNA damage, mitochondrial function and apoptosis in SNK-6 cells. SNK-6 cells were treated by ASA with different concentrations of $0,1,2,5$, and $10 \mathrm{mM}$ for $24 \mathrm{~h}$, and then the cells were used for biomedical analysis. (A) ROS formation, $n=5$. (B) 3-nitrotyrosine (3-NT) formation, $n=5$. (C) 8-OHdG formation, $n=5$. (D) Representative western blotting bands for $\gamma \mathrm{H} 2 \mathrm{AX}$. (E) Quantitation of $\gamma \mathrm{H} 2 \mathrm{AX}$ formation for (D), $n=5$. (F) Intracellular ATP level, $n=5$. (G) Mitochondrial membrane potential $(\Delta \Psi \mathrm{m})$ by TMRE fluorescence, $n=5$. (H) Caspase-3 activity, $n=5$. (I) Apoptosis rate by TUNEL assay, $n=5$. (J) Representative pictures for (I). ${ }^{\star} P<0.05$, vs. $0 \mathrm{mM}$ group; $\mathbb{I}_{P}<0.05$, vs. $2 \mathrm{mM}$ group; ${ }^{\Psi} P<0.05$, vs. $5 \mathrm{mM}$ group. Results are expressed as mean \pm SEM.

respectively, while ASA-5 $\mathrm{mM}$ treatment had no effect (see Figure 4D). We also measured the related protein levels of those genes, including Zta and EA-D. The results showed that treatments of ASA $-5 \mathrm{mM}$, ASA- $2 \mathrm{mM} / \mathrm{CDM}$ and ASA-5 $\mathrm{mM} / \mathrm{CDM}$ decreased Zta protein levels by 42,66 , and $71 \%$, respectively, and decreased EA-D protein levels by 49, 76, and $82 \%$, respectively (see Figures 4E,F). Finally, we measured the effect of aspirin and chidamide on EBV replication (see Figure 4G). We found that treatments of ASA-5 mM, ASA-2 $\mathrm{mM} / \mathrm{CDM}$ and ASA-5 mM/CDM decreased EBV genome copies by 25,57 , and $79 \%$, respectively. Our results indicate that ASA treatment alone slightly suppresses VEGF expression and EBV replication, while a combination with chidamide significantly potentiates this effect.

\section{Aspirin Treatment Suppresses Cell Proliferation, and Chidamide Significantly Potentiates This Effect in SNK-6 Cells}

We evaluated the effect of aspirin and chidamide on in vitro tumor cell growth in SNK-6 cells. We first measured the effect of aspirin on thymidine incorporation assay. The results showed that treatments of ASA- $5 \mathrm{mM}$, ASA-2 mM/CDM and ASA-5 $\mathrm{mM} / \mathrm{CDM}$ decreased thymidine incorporation by 22,50 , and $76 \%$, respectively (see Figure 5A) compared to the control (CTL) group, and decreased MTT assay by 8.0, 13, and 22\%, respectively (see Figure 5B), in addition to decreasing colony formation by $26 \%, 55$ and 68 , respectively (see Figure 5C), while ASA-2 mM group showed no effect. We then measured the invasion and migration properties of the treated cells. We found that treatments of ASA-5 mM, ASA-2 mM/CDM and ASA-5 mM/CDM decreased cell invasion by 28,49 , and $73 \%$, respectively (see Figure 5D) compared to the control (CTL) group, and that they decreased cell migration by 22,35 , and $66 \%$, respectively (see Figure 5E). Finally, we measured the effect of aspirin on Ki-67 positive ratio using immunostaining. The results showed that treatments of ASA-5 mM, ASA-2 mM/CDM and ASA- $5 \mathrm{mM} / \mathrm{CDM}$ decreased the Ki-67 positive ratio by 27,43 , and $71 \%$, respectively (see Figures $5 \mathbf{F}, \mathbf{G}$ ), while the ASA-2 mM group showed no effect. Our results indicate that aspirin alone slightly decreases cell proliferation, and chidamide significantly potentiates this effect.

\section{Aspirin Suppresses Tumor Growth and EBV Replication in in vivo Xenograft Tumor Development, and Chidamide Significantly Potentiates This Effect}

We evaluated the effect of aspirin on tumor growth and EBV replication in in vivo xenograft tumor tissues. The $2 \times 10^{6}$ viable treated tumor cells were washed, harvested in PBS, and then injected into the lateral tail vein in a volume of $0.1 \mathrm{ml}$. Mice were monitored for changes in body weight and sacrificed when values fell below $20 \%$ of their initial weight. We first measured the effect of aspirin on gene expression. The results showed that treatments of ASA-100/CDM and ASA-400/CDM decreased VEGF mRNA levels by 35 and 55\%, respectively, and they decreased BMRF1 mRNA levels by 29 and 39\%, respectively, compared to the control (CTL) group. Furthermore, treatments of ASA-400, ASA-100/CDM and ASA-400/CDM decreased BZLF1 mRNA 


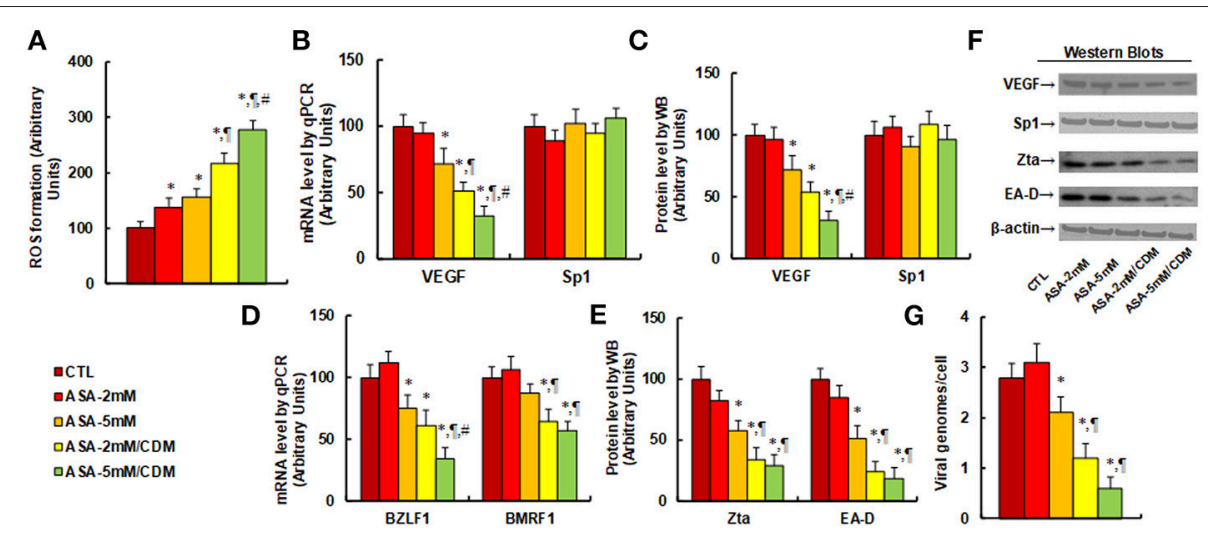

FIGURE 4 | Aspirin treatment increases ROS generation and suppresses VEGF expression and EBV replication in SNK-6 cells. Chidamide significantly potentiates this effect. The SNK-6 cells were treated with control (CTL) alone, $2 \mathrm{mM}$ aspirin (ASA) alone (ASA-2 mM), $5 \mathrm{mM}$ ASA alone (ASA-5 mM), combination of 2 mM ASA and $3 \mu \mathrm{M}$ CDM (ASA-2 mM/CDM), or combination of $5 \mathrm{mM}$ ASA, and $3 \mu \mathrm{M}$ CDM (ASA-5mM/CDM) for $24 \mathrm{~h}$, and the cells were harvested for further analysis. (A) ROS formation, $n=5$. (B) mRNA levels by qPCR for VEGF and Sp1, $n=4$. (C) Protein quantitation for VEGF and Sp1, $n=5$. (D) mRNA level by qPCR for BZLF1 and BMRF1, $n=4$. (E) Protein quantitation for Zta and EA-D, $n=5$. (F) Representative pictures of western blots for (C,E). (G) EBV viral genomes/cell by qPCR, $n=4$. ${ }^{\star} P<0.05$, vs. CTL group; I $P<0.05$, vs. ASA-5 mM group; $\# P<0.05$, vs. ASA-2 mM/CDM group. Results are expressed as mean \pm SEM.
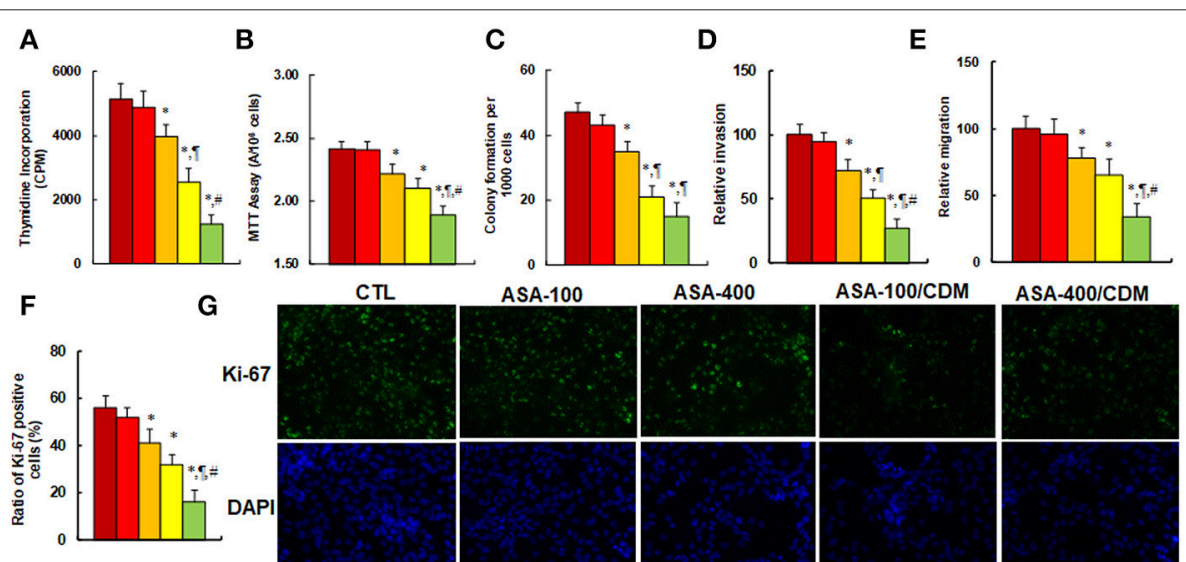

Ki-67
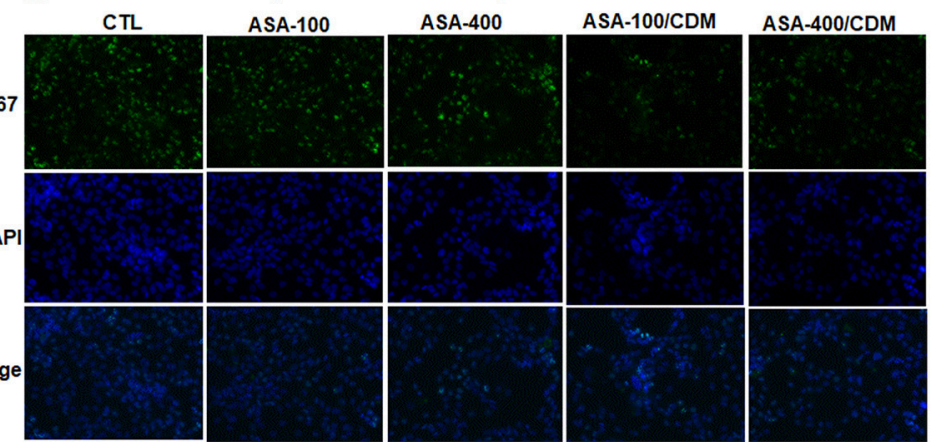

FIGURE 5 | Aspirin treatment suppresses cell proliferation, and chidamide significantly potentiates this effect in SNK-6 cells. The SNK-6 cells were treated with control (CTL) alone, $2 \mathrm{mM}$ aspirin (ASA) alone (ASA-2 mM), $5 \mathrm{mM}$ ASA alone (ASA-5 mM), combination of $2 \mathrm{mM}$ ASA and $3 \mu \mathrm{M}$ CDM (ASA-2 mM/CDM), and combination of $5 \mathrm{mM}$ ASA and $3 \mu \mathrm{M}$ CDM (ASA $-5 \mathrm{mM} / \mathrm{CDM}$ ) for $24 \mathrm{~h}$, and the cells were harvested for further analysis. (A) Cell proliferation analysis by thymidine incorporation,

$n=5$. (B) Cell metabolic activity by MTT assay, $n=5$. (C) Colony formation assay in soft agar, $n=5$. (D) Cell migration assay, $n=4$. (E) Cell invasion assay, $n=4$. (F) Quantitation of Ki-67 positive cells, $n=3$. (G) Representative picture for (F). ${ }^{\star} P<0.05$, vs. CTL group; II $P<0.05$, vs. ASA-5 mM group; \# $P<0.05$, vs. ASA-2 $\mathrm{mM} / \mathrm{CDM}$ group. Results are expressed as mean \pm SEM. Results are expressed as mean \pm SEM.

levels by 29, 41, and 66\%, respectively (see Figure 6A). We then measured the protein levels of these genes. The results showed that treatments of ASA-400, ASA-100/CDM and ASA$400 / \mathrm{CDM}$ decreased VEGF by 41,61 , and $81 \%$, respectively, and treatments of ASA-100/CDM and ASA-400/CDM decreased Zta by 45 and $53 \%$. They also decreased EA-D by 52 and $56 \%$, respectively, while treatment of the ASA-400 group had no effect (see Figures 6B,C). We measured the effect of aspirin on oxidative stress in the tumor tissues. The results showed that treatments of ASA-400, ASA-100/CDM, and ASA-400/CDM increased superoxide anion $\left(\mathrm{O}_{2}^{-} \cdot\right)$ in vivo release to 212,232 , and $312 \%$, respectively, compared to the control group (see Figure 6D). We also measured the EBV DNA copies in the tumor tissues. We found that treatments of ASA-100/CDM and ASA-400/CDM decreased EBV DNA copies by 61 and $81 \%$, respectively, compared to the control group (see Figure $6 \mathrm{E}$ ). We then measured lung tumor nodule formation from the tumor tissues and found that treatments of ASA-400, ASA-100/CDM, 


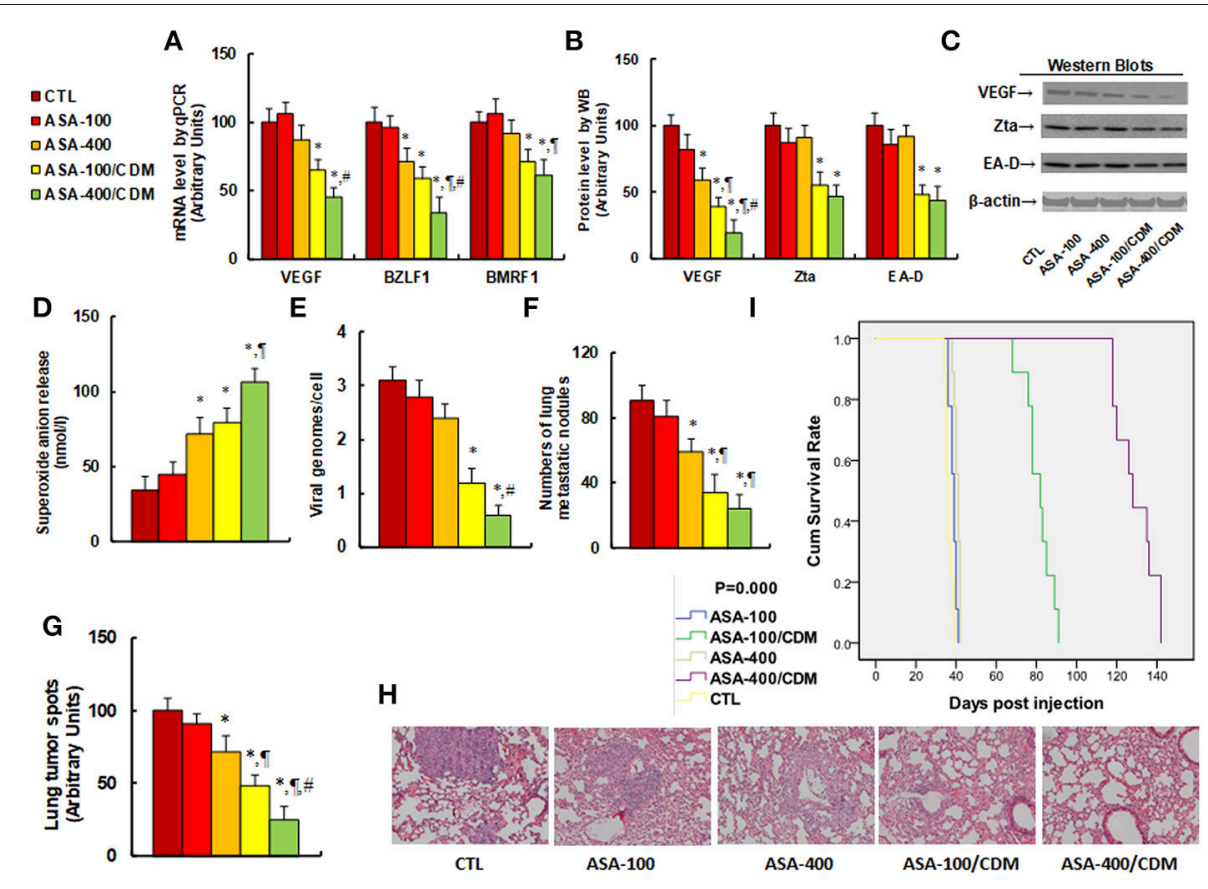

FIGURE 6 | Aspirin suppresses tumor growth and EBV replication in in vivo xenograft tumor development, and chidamide significantly potentiates this effect. The nude mice were injected with SNK-6 cells for in vivo xenograft tumor development study. The $2 \times 10^{6}$ viable treated tumor cells were washed, harvested in PBS, and then injected into the lateral tail vein in a volume of $0.1 \mathrm{ml}$. The mice were then treated with chemical control (CTL) alone, $100 \mathrm{mg} / \mathrm{kg}$ aspirin (ASA-100), $400 \mathrm{mg} / \mathrm{kg}$ aspirin (ASA-400), 100 mg/kg aspirin plus 25 mg/kg CDM (ASA-100/CDM), or 400 mg/kg aspirin plus 25 mg/kg CDM (ASA-400/CDM). Mice were monitored for changes in body weight and sacrificed when values fell below $20 \%$ of their initial weight for further analysis. (A) mRNA level by qPCR, $n=4$. (B) Protein quantitation by Western Blots, $n=5$. (C) Representative pictures for (B). (D) Superoxide anion release from tumor tissues, $n=5$. (E) EBV viral genomes/cell by qPCR, $n=5$. (F) Tumor colony formation in lung, $n=5$. (G) Mice were killed upon 20\% weight loss, and organs were harvested for terminal analysis. Formalin-fixed, paraffin-embedded tumor tissue from the lungs were sectioned to $4 \mathrm{~mm}$ thickness, and the histopathological analyses were performed with H\&E staining. Images were taken using a Carl Zeiss MIRAX MIDI slide scanner, and the lung tumor spots were analyzed using a 3DHISTECH Pannoramic Viewer, $n=5$. (H) Representative picture by $\mathbf{H} \& \mathbf{E}$ staining for (G). (I) Kaplan-Meier analysis comparing survival of mice between each treatment group, $P$-value represents log-rank Mantel-Cox test result, $n=10$. ${ }^{*} P<0.05$, vs. CTL group; Il $P<0.05$, vs. ASA-400 group; $\# P<0.05$, vs. ASA-100/CDM group. Results are expressed as mean \pm SEM.

and ASA-400/CDM decreased lung tumor nodule formation by 35,63 , and $74 \%$, respectively, compared to the control group (see Figure 6F). Additionally, we evaluated the effect of aspirin on the formation of lung tumor spots by $\mathrm{H} \& \mathrm{E}$ staining (see Figures 6G,H). The results showed that treatments of ASA400, ASA-100/CDM, and ASA-400/CDM decreased lung tumor spots by 28,52 , and $75 \%$, respectively. Finally, we measured the effect of aspirin on mouse survival rate using Kaplan-Meier analysis (see Figure 6I). We found that treatment of aspirin alone, including the ASA-100 and ASA-400 group, had little effect on mouse survival, while treatments with the addition of chidamide, including the ASA-100/CDM and ASA-400/CDM groups, resulted in significantly increased mouse survival - to 225 and $358 \%$ compared to the control (CTL) group, respectively. Our results indicate that aspirin alone has a small effect on tumor growth and EBV replication, while a combination of aspirin and chidamide significantly potentiates aspirin-mediated in vivo tumor growth and EBV suppression.

\section{DISCUSSION}

In this study, we demonstrated that aspirin inhibits VEGF expression through histone methylation with subsequently decreased association of Spl on the VEGF promoter. In addition, aspirin modulates mitochondrial function and increases ROS generation with subsequent suppression of EBV replication. This is a potential mechanism of aspirin in suppression of EBVassociated NKTCL tumor growth. Furthermore, we found that the suppression effect of aspirin on NKTCL tumor growth is significantly potentiated with the addition of chidamide. This provides a new strategy for the clinical treatment of NKTCL.

\section{Aspirin-Mediated VEGF Suppression and Tumor Suppression}

In this study, we showed that aspirin inhibits NKTCL tumor growth through VEGF suppression, which is consistent with previous reports on the effects of aspirin on tumor suppression $(5,7,8)$. It has been reported that histone methylation is involved with VEGF expression (36), and that Sp1 is involved in VEGF expression and tumor growth (37). Our results showed that aspirin increases histone methylation on the promoter of VEGF (12), and subsequently decreases the binding ability of Sp1 to the VEGF promoter in NKTCL cells, while Sp1 expression does not change. On the other hand, other reports have shown that aspirin inhibits tumor growth through direct downregulation of Sp1 in colon cancer cells (33); this discrepancy may be due to different 


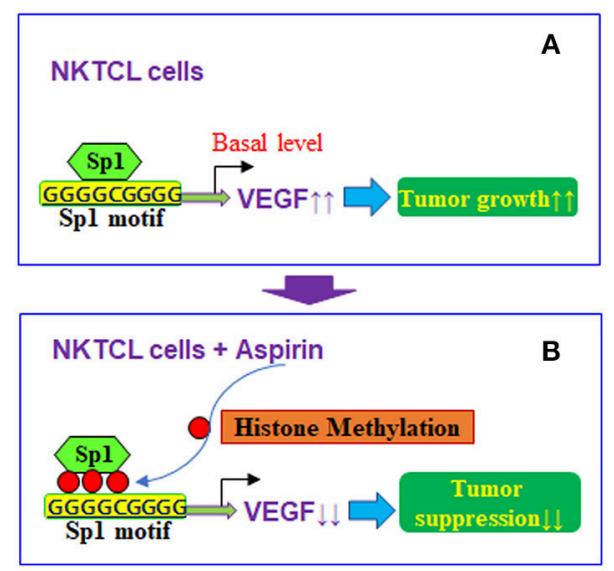

FIGURE 7 | Proposed mechanisms for aspirin-mediated VEGF suppression in NKTCL cells. (A) VEGF expression in NKTCL cells with tumor growth. (B) VEGF suppression by aspirin-mediated histone methylation and subsequent Sp1 dissociation on the VEGF promoter in NKTCL cells with tumor suppression.

gene regulation systems of $\mathrm{Sp} 1$ in different cells. Furthermore, we found that aspirin-induced VEGF expression is involved in $\mathrm{H} 3 \mathrm{~K} 27 \mathrm{me} 3$ histone modification. It has been reported that polycomb repressive complex 2 (PRC2) is responsible for methylation of histone $\mathrm{H} 3$ on lysine 27 (H3K27me3) (38), and that PRC2 comprises the EZH1/2 catalytic subunit, SUZ12, EED, and RBBP7/4 (39). Either knockdown of the EZH2 subunit by siRNA or the EED specific inhibitor EED226 (34) should be able to block PRC2-induced H3K27me3 methylation. Our results showed that treatments of both EZH2 siRNA and EED specific inhibitor EED226 completely restored aspirin-induced H3K27me 3 modification and VEGF suppression. This provides evidence that aspirin-induced VEGF suppression is involved in $\mathrm{H} 3 \mathrm{~K} 27 \mathrm{me} 3$ modification on the VEGF promoter.

\section{Aspirin-Mediated Mitochondrial Function and EBV Inhibition}

It has been reported that aspirin modulates ROS generation (40) and mitochondrial function $(15,41)$. In this study, we showed that aspirin increases oxidative stress and subsequent DNA damage. Furthermore, it decreases ATP generation and mitochondrial membrane potential with subsequently increased apoptosis, which is consistent with previous reports. The potential mechanism of aspirin in the modulation of mitochondrial function is complicated; it can be explained by speculations that aspirin may modulate mitochondrial biogenesis (42), increase mitochondrial fatty acid oxidation (43), or modulate mitochondrial voltage-dependent anion channels (VDAC) (44). In addition, our data showed that aspirin slightly suppresses EBV replication and decreases viral gene expression of BZLF1 and BMRF1 and the subsequent coding proteins Zta and EA-D $(45,46)$. BZLF1 and BMRF1 are potential markers of EBV activation during the latent stage, and the suppression of Zta and EA-D may indicate a potential effect of aspirin on EBV DNA removal. This can be explained because aspirin-mediated mitochondrial dysfunction and ROS generation triggers EBV DNA damage, subsequently suppressing EBV replication, which is consistent with our previous findings (20).

\section{Role of Chidamide in Aspirin-Mediated Tumor Suppression}

As a novel histone deacetylase inhibitor, chidamide (CDM) has been recently used for several clinical trials as a potential antitumor drug in China. It shows some effects on cancer inhibition in T-cell lymphoma (19,47-49), multiple myeloma (50), and pancreatic cancer (51), although there are no reports regarding the effects of chidamide alone on NKTCL inhibition. In this study, we showed that chidamide (CDM) alone has a small effect on NKTCL tumor growth and EBV replication, while when it is used together with aspirin, it significantly potentiated aspirinmediated tumor suppression in NKTCL cells. NKTCL is an EBVassociated tumor with a tendency to be relapsed or refractory and is resistant to many chemotherapies, and a combination of aspirin and chidamide (ASP/CDM)-mediated ROS overgeneration could directly bring damage to EBV DNA and inhibit EBV replication (20). Furthermore, ASP/CDM-mediated VEGF pathway suppression could significantly suppress tumor growth (21). Our data provides a new strategy for NKTCL treatment through suppression of the VEGF signaling pathway and ROS generation.

\section{CONCLUSIONS}

Taken together, aspirin-mediated suppression of VEGF expression and tumor growth in NKTCL cells can be conceptualized in Figure 7. We showed that aspirin suppresses VEGF expression through epigenetic changes on the VEGF promoter with increased histone methylation. Furthermore, it modulates mitochondrial function with increased ROS formation and apoptosis in NKTCL tumor cells. Aspirin alone slightly inhibits NKTCL tumor growth, while this effect is significantly potentiated with the addition of the histone deacetylase inhibitor chidamide. We conclude that aspirin inhibits NKTCL through VEGF suppression and modulation of mitochondrial formation. The addition of chidamide significantly potentiates aspirin-mediated NKTCL inhibition. This provides a new strategy for anti-tumor drug development to inhibit EBV-associated NKTCL tumor growth.

\section{ETHICS STATEMENT}

The animal protocol conformed to US NIH guidelines (Guide for the Care and Use of Laboratory Animals, No. 85-23, revised 1996), and was reviewed and approved by the Institutional Animal Care and Use Committee from Peking University Shenzhen Hospital and Wuhan University.

\section{AUTHOR CONTRIBUTIONS}

PY wrote the paper. PY, LL, and WX designed, analyzed the data and interpreted the experiments. ML, AY, XH, and WX 
performed vector constructions and gene expression analysis. QG and ZW performed statistical analysis and part of the mice experiments. QC and ZY performed gene analysis and part of the mapping analysis. HZ, JL, and YJ performed the remaining experiments. All authors read and approved the final manuscript.

\section{FUNDING}

This study was financially supported by The National Natural Science Foundation of China, Project \#:81772097; Bureau of Public Health of Hainan Province Key

\section{REFERENCES}

1. Wang ZY, Liu QF, Wang H, Jin J, Wang WH, Wang SL, et al. Clinical implications of plasma epstein-barr virus DNA in early-stage extranodal nasal-type NK/T-cell lymphoma patients receiving primary radiotherapy. Blood (2012) 120:2003-10. doi: 10.1182/blood-2012-06-435024

2. El-Sharkawy A, Al Zaidan L, Malki A. Epstein-barr virus-associated malignancies: roles of viral oncoproteins in carcinogenesis. Front Oncol. (2018) 8:265. doi: 10.3389/fonc.2018.00265

3. Chen YW, Guo T, Shen L, Wong KY, Tao Q, Choi WW, et al. Receptortype tyrosine-protein phosphatase kappa directly targets STAT3 activation for tumor suppression in nasal NK/T-cell lymphoma. Blood (2015) 125:1589-600. doi: 10.1182/blood-2014-07-588970

4. Komabayashi Y, Kishibe K, Nagato T, Ueda S, Takahara M, Harabuchi Y. Circulating epstein-barr virus-encoded micro-RNAs as potential biomarkers for nasal natural killer/T-cell lymphoma. Hematol Oncol. (2017) 35:655-63. doi: $10.1002 /$ hon. 2360

5. Chan AT, Arber N, Burn J, Chia WK, Elwood P, Hull MA, et al. Aspirin in the chemoprevention of colorectal neoplasia: an overview. Cancer Prev Res. (2012) 5:164-78. doi: 10.1158/1940-6207.CAPR-11-0391

6. Manzano A, Perez-Segura P. Colorectal cancer chemoprevention: is this the future of colorectal cancer prevention?. Sci World J. (2012) 2012:327341. doi: $10.1100 / 2012 / 327341$

7. Baron JA, Cole BF, Sandler RS, Haile RW, Ahnen D, Bresalier R, et al. A randomized trial of aspirin to prevent colorectal adenomas. $N$ Engl J Med. (2003) 348:891-9. doi: 10.1056/NEJMoa021735

8. Chae YK, Trinh L, Jain P, Wang X, Rozovski U, Wierda WG, et al. Statin and aspirin use is associated with improved outcome of FCR therapy in relapsed/refractory chronic lymphocytic leukemia. Blood (2014) 123:1424-6. doi: 10.1182/blood-2013-07-517102

9. Chen WY, Holmes MD. Role of aspirin in breast cancer survival. Curr Oncol Rep. (2017) 19:48. doi: 10.1007/s11912-017-0605-6

10. Drew DA, Cao Y, Chan AT. Aspirin and colorectal cancer: the promise of precision chemoprevention. Nat Rev Cancer (2016) 16:173-86. doi: $10.1038 / \mathrm{nrc} .2016 .4$

11. Dai X, Yan J, Fu X, Pan Q, Sun D, Xu Y, et al. Aspirin inhibits cancer metastasis and angiogenesis via targeting heparanase. Clin Cancer Res. (2017) 23:6267-78. doi: 10.1158/1078-0432.CCR-17-0242

12. Guo Y, Liu Y, Zhang C, Su ZY, Li W, Huang MT, et al. The epigenetic effects of aspirin: the modification of histone $\mathrm{H} 3$ lysine 27 acetylation in the prevention of colon carcinogenesis in azoxymethane- and dextran sulfate sodium-treated CF-1 mice. Carcinogenesis (2016) 37:616-24. doi: 10.1093/carcin/bgw042

13. Saha S, Mukherjee S, Khan P, Kajal K, Mazumdar M, Manna A, et al. Aspirin suppresses the acquisition of chemoresistance in breast cancer by disrupting an NFkappaB-IL6 signaling axis responsible for the generation of cancer stem cells. Cancer Res. (2016) 76:2000-12. doi: 10.1158/0008-5472.CAN$15-1360$

14. Tahara T, Shibata T, Nakamura M, Yamashita H, Yoshioka D, Okubo M, et al. Chronic aspirin use suppresses $\mathrm{CDH} 1$ methylation in human gastric mucosa. Dig Dis Sci. (2010) 55:54-9. doi: 10.1007/s10620-008-0701-4
Project \#:14A110065; Shenzhen Scientific and Technical Innovation Committee Project \#:JCYJ20150403091443305 \& JCYJ20160429185235132; Shenzhen SanMing Project \#:SZSM201612004 \& SZSM201612079; Shenzhen Science and Technology Planning Project \#:JCYJ2017081610 5345191.

\section{SUPPLEMENTARY MATERIAL}

The Supplementary Material for this article can be found online at: https://www.frontiersin.org/articles/10.3389/fonc. 2018.00679/full\#supplementary-material
15. Raza H, John A. implications of altered glutathione metabolism in aspirininduced oxidative stress and mitochondrial dysfunction in HepG2 cells. PLoS ONE (2012) 7:e36325. doi: 10.1371/journal.pone.0036325

16. Kanikarla-Marie P, Lam M, Sorokin AV, Overman MJ, Kopetz S, Menter DG. Platelet metabolism and other targeted drugs; potential impact on immunotherapy. Front Oncol. (2018) 8:107. doi: 10.3389/fonc.2018.00107

17. Hegedus L, Padanyi R, Molnar J, Paszty K, Varga K, Kenessey I, et al. Histone deacetylase inhibitor treatment increases the expression of the plasma membrane $\mathrm{Ca}(2+)$ Pump PMCA4b and inhibits the migration of melanoma cells independent of ERK. Front Oncol. (2017) 7:95. doi: $10.3389 /$ fonc. 2017.00095

18. Gong K, Xie J, Yi H, Li W. CS055 (Chidamide/HBI-8000), a novel histone deacetylase inhibitor, induces G1 arrest, ROS-dependent apoptosis and differentiation in human leukemia cells. Biochem J. (2012) 443:735-46. doi: 10.1042/BJ20111685

19. Shi Y, Dong M, Hong X, Zhang W, Feng J, Zhu J, et al. Results from a multicenter, open-label, pivotal phase II study of chidamide in relapsed or refractory peripheral t-cell lymphoma. Ann Oncol. (2015) 26:1766-71. doi: 10.1093/annonc/mdv237

20. Yu H, Zhang H, Chu Z, Ruan Q, Chen X, Kong D, et al. Combination of betulinic acid and chidamide synergistically inhibits epstein-barr virus replication through over-generation of reactive oxygen species. Oncotarget (2017) 8:61646-61. doi: 10.18632/oncotarget.18661

21. Zhang H, Li L, Li M, Huang X, Xie W, Xiang W, et al. Combination of betulinic acid and chidamide inhibits acute myeloid leukemia by suppression of the HIF1alpha pathway and generation of reactive oxygen species. Oncotarget (2017) 8:94743-58. doi: 10.18632/oncotarget.21889

22. Zou Y, Lu Q, Zheng D, Chu Z, Liu Z, Chen H, et al. Prenatal levonorgestrel exposure induces autism-like behavior in offspring through ERbeta suppression in the amygdala. Mol Autism. (2017) 8:46. doi: 10.1186/s13229-017-0159-3

23. Yao D, Shi W, Gou Y, Zhou X, Yee Aw T, Zhou Y, et al. Fatty acidmediated intracellular iron translocation: a synergistic mechanism of oxidative injury. Free Radic Biol Med. (2005) 39:1385-98. doi: 10.1016/j.freeradbiomed.2005.07.015

24. Kong D, Zhan Y, Liu Z, Ding T, Li M, Yu H, et al. SIRT1-mediated ERbeta suppression in the endothelium contributes to vascular aging. Aging Cell. (2016) 5:1092-102. doi: 10.1111/acel.12515

25. Verma D, Thompson J, Swaminathan S. Spironolactone blocks epstein-barr virus production by inhibiting EBV SM protein function. Proc Natl Acad Sci USA. (2016) 113:3609-14. doi: 10.1073/pnas.1523686113

26. Zuo L, Yu H, Liu L, Tang Y, Wu H, Yang J, Zhu M, Du S, Zhao L, Cao L, et al. The copy number of epstein-barr virus latent genome correlates with the oncogenicity by the activation level of LMP1 and NF-kappaB. Oncotarget (2015) 6:41033-44. doi: 10.18632/oncotarget.5708

27. Hui KF, Chiang AK. Suberoylanilide hydroxamic acid induces viral lytic cycle in epstein-barr virus-positive epithelial malignancies and mediates enhanced cell death. Int J Cancer (2010) 126:2479-89. doi: 10.1002/ijc.24945

28. Rose C, Green M, Webber S, Kingsley L, Day R, Watkins S, et al. Detection of epstein-barr virus genomes in peripheral blood b cells from solid-organ 
transplant recipients by fluorescence in situ hybridization. J Clin Microbiol. (2002) 40:2533-44. doi: 10.1128/JCM.40.7.2533-2544.2002

29. Liu Y, Peterson DA, Kimura H, Schubert D. Mechanism of cellular 3-(4,5dimethylthiazol-2-yl)-2,5-diphenyltetrazolium bromide (MTT) reduction. J Neurochem. (1997) 69:581-93. doi: 10.1046/j.1471-4159.1997.69020581.x

30. Somasundaram K, El-Deiry WS. Inhibition of p53-mediated transactivation and cell cycle arrest by E1A through its p300/CBP-interacting region. Oncogene (1997) 14:1047-57. doi: 10.1038/sj.onc.1201002

31. Han HJ, Russo J, Kohwi Y, Kohwi-Shigematsu T. SATB1 reprogrammes gene expression to promote breast tumour growth and metastasis. Nature (2008) 452:187-93 . doi: 10.1038/nature06781

32. Yu OM, Benitez JA, Plouffe SW, Ryback D, Klein A, Smith J, et al. YAP and MRTF-A, transcriptional co-activators of rhoa-mediated gene expression, are critical for glioblastoma tumorigenicity. Oncogene (2018) 37:5492-507. doi: 10.1038/s41388-018-0301-5

33. Pathi S, Jutooru I, Chadalapaka G, Nair V, Lee SO, Safe S. aspirin inhibits colon cancer cell and tumor growth and downregulates specificity protein (Sp) transcription factors. PLoS ONE (2012) 7:e48208. doi: 10.1371/journal.pone.0048208

34. Qi W, Zhao K, Gu J, Huang Y, Wang Y, Zhang H, et al. An allosteric PRC2 inhibitor targeting the H3K27me3 binding pocket of EED. Nat Chem Biol. (2017) 13:381-8. doi: 10.1038/nchembio.2304

35. Li Y, Chen K, Zhou Y, Xiao Y, Deng M, Jiang Z, et al. A new strategy to target acute myeloid leukemia stem and progenitor cells using chidamide, a histone deacetylase inhibitor. Curr Cancer Drug Targets (2015) 15:493-503. doi: 10.2174/156800961506150805153230

36. Clifford RL, John AE, Brightling CE, Knox AJ. Abnormal histone methylation is responsible for increased vascular endothelial growth factor 165a secretion from airway smooth muscle cells in asthma. J Immunol. (2012) 189:819-31. doi: 10.4049/jimmunol.1103641

37. Su F, Geng J, Li X, Qiao C, Luo L, Feng J, et al. SP1 promotes tumor angiogenesis and invasion by activating vegf expression in an acquired trastuzumabresistant ovarian cancer model. Oncol Rep. (2017) 38:2677-84. doi: $10.3892 / o r .2017 .5998$

38. Boros J, Arnoult N, Stroobant V, Collet JF, Decottignies A. Polycomb repressive complex 2 and h3K27me3 cooperate with H3K9 methylation to maintain heterochromatin protein 1alpha at chromatin. Mol Cell Biol. (2014) 34:3662-74. doi: 10.1128/MCB.00205-14

39. Margueron R, Reinberg D. The polycomb complex PRC2 and its mark in life. Nature (2011) 469:343-9. doi: 10.1038/nature09784

40. Ou HC, Lee WJ, Wu CM, Chen JF, Sheu WH. Aspirin prevents resistininduced endothelial dysfunction by modulating AMPK, ROS,Akt/eNOS signaling. J Vasc Surg. (2012) 55:1104-15. doi: 10.1016/j.jvs.2011.10.011

41. Raza H, John A, Shafarin J. Potentiation of LPS-induced apoptotic cell death in human hepatoma HepG2 cells by aspirin via ros and mitochondrial dysfunction: protection by N-Acetyl Cysteine. PLoS ONE (2016) 11:e0159750. doi: 10.1371/journal.pone.0159750
42. Kamble P, Selvarajan K, Aluganti Narasimhulu C, Nandave M, Parthasarathy $\mathrm{S}$. Aspirin may promote mitochondrial biogenesis via the production of hydrogen peroxide and the induction of sirtuin1/PGC-1alpha genes. Eur J Pharmacol. (2013) 699:55-61. doi: 10.1016/j.ejphar.2012.11.051

43. Uppala R, Dudiak B, Beck ME, Bharathi SS, Zhang Y, Stolz DB, et al. Aspirin increases mitochondrial fatty acid oxidation. Biochem Biophys Res Commun. (2017) 482:346-51. doi: 10.1016/j.bbrc.2016.11.066

44. Tewari D, Majumdar D, Vallabhaneni S, Bera AK. Aspirin induces cell death by directly modulating mitochondrial voltage-dependent anion channel (VDAC). Sci Rep. (2017) 7:45184. doi: 10.1038/srep45184

45. Countryman JK, Gradoville L, Miller G. Histone hyperacetylation occurs on promoters of lytic cycle regulatory genes in epstein-barr virus-infected cell lines which are refractory to disruption of latency by histone deacetylase inhibitors. J Virol. (2008) 82:4706-19. doi: 10.1128/JVI.00116-08

46. Neuhierl B, Delecluse HJ. The epstein-barr virus bmrfl gene is essential for lytic virus replication. J Virol. (2006) 80:5078-81. doi: 10.1128/JVI.80.10.5078-5081.2006

47. Shi Y, Jia B, Xu W, Li W, Liu T, Liu P, et al. Chidamide in relapsed or refractory peripheral $\mathrm{T}$ cell lymphoma: a multicenter real-world study in China. J Hematol Oncol. (2017) 10:69. doi: 10.1186/s13045-0170439-6

48. Ji MM, Huang YH, Huang JY, Wang ZF, Fu D, Liu H, et al. Histone modifier gene mutations in peripheral t-cell lymphoma not otherwise specified. Haematologica (2018) 103:679-87. doi: 10.3324/haematol.2017.182444

49. Moskowitz AJ, Horwitz SM. Targeting histone deacetylases in T-cell lymphoma. Leuk Lymphoma. (2017) 58:1306-19. doi: 10.1080/10428194.2016.1247956

50. He J, Chen Q, Gu H, Chen J, Zhang E, Guo X, et al. Therapeutic effects of the novel subtype-selective histone deacetylase inhibitor chidamide on myeloma-associated bone disease. Haematologica (2018) 103:1369-79. doi: 10.3324/haematol.2017.181172

51. He M, Qiao Z, Wang Y, Kuai Q, Li C, Wang Y, et al. Chidamide inhibits aerobic metabolism to induce pancreatic cancer cell growth arrest by promoting Mcl-1 degradation. PLoS ONE (2016) 11:e0166896. doi: 10.1371/journal.pone.0166896

Conflict of Interest Statement: The authors declare that the research was conducted in the absence of any commercial or financial relationships that could be construed as a potential conflict of interest.

Copyright $\odot 2019$ Zhang, Lu, Jiao, Chen, Li, Wang, Yu, Huang, Yao, Gao, Xie, Li and Yao. This is an open-access article distributed under the terms of the Creative Commons Attribution License (CC BY). The use, distribution or reproduction in other forums is permitted, provided the original author(s) and the copyright owner(s) are credited and that the original publication in this journal is cited, in accordance with accepted academic practice. No use, distribution or reproduction is permitted which does not comply with these terms. 